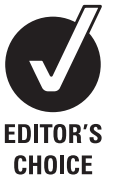

CHOICE

\title{
The association between cerebral amyloid angiopathy and intracerebral haemorrhage: systematic review and meta-analysis
}

\author{
Neshika Samarasekera, Colin Smith, Rustam Al-Shahi Salman
}

\begin{abstract}
- Additional materials are published online only. To view these files please visit the journal online (http://jnnp.bmj. com/content/83/3.toc).
\end{abstract}

Division of Clinical Neurosciences, Centre for Clinical Brain Sciences, University of Edinburgh, Bramwell Dott Building, Western General Hospital, Edinburgh, UK

Correspondence to Dr R Al-Shahi Salman, Bramwell Dott Building, Division of Clinical Neurosciences, Western General Hospital, Crewe Road, Edinburgh EH4 2XU, UK; rustam.al-shahi@ed.ac.uk

Received 21 April 2011 Revised 13 July 2011 Accepted 3 October 2011 Published Online First 5 November 2011

\begin{abstract}
Background The aim of this study was to determine the strength of the association between intracerebral haemorrhage (ICH) and cerebral amyloid angiopathy (CAA) in a systematic review of published neuropathological studies.

Methods In April 2011, Ovid Medline (from 1950) and Embase (from 1980) were searched for neuropathological studies that quantified the prevalence of CAA in patients with $\mathrm{ICH}$ and in a control group without ICH. Two authors extracted data from each study and meta-analysed their results using a random effects model.

Results 10 neuropathological cross sectional or case control studies were identified, involving 481 cases with $\mathrm{ICH}$ and 3219 controls. There was no association between CAA and ICH in any location IOR 1.21, 95\% Cl 0.87 to $1.68 ; 10$ studies, I $I^{2} 29 \%$ ), deep ICH (OR 0.81, 95\% Cl 0.30 to 2.19; five studies, $I^{2} 58 \%$ ) or cerebellar ICH (OR $2.05,95 \% \mathrm{Cl} 0.55$ to 7.63 ; four studies, $\mathrm{I}^{2} 0 \%$ ). CAA was significantly associated with lobar ICH, both overall (OR 2.21, 95\% Cl 1.09 to 4.45; six studies, $\mathrm{I}^{2} 40 \%$ ) and in the three studies where average ages for cases and controls were comparable (OR 3.24, 95\% Cl 1.02 to 10.26).

Conclusions There is an association between CAA and lobar ICH, although the association might be stronger if potential confounding factors, distinctive clinical and imaging features of ICH due to CAA and CAA neuropathological severity are taken into account.
\end{abstract}

\section{INTRODUCTION}

During the past decade, spontaneous (non-traumatic) intracerebral haemorrhage (ICH) accounted for $\sim 10 \%$ of strokes in high income countries and $\sim 20 \%$ of strokes in low/middle income countries, where the 1 month case fatalities were $25-35 \%$ and $30-48 \%$, respectively. ${ }^{1}$ Although time trends have varied between regions, the case fatality 1 month after ICH has remained $\sim 40 \%$ across the globe during the past few decades. ${ }^{2}$ Understanding that systemic arterial hypertension is the strongest modifiable risk factor for ICH led to trials of secondary prevention with antihypertensive drugs, ${ }^{3}{ }^{4}$ which appear to improve outcome for survivors of ICH (regardless of its location). ${ }^{5}$ Further improvements in outcome could arise from a better understanding of the causes of $\mathrm{ICH}$. Because survivors of lobar ICH appear to be at a higher risk of recurrent $\mathrm{ICH}$ than survivors of deep $\mathrm{ICH}^{6}$ the causes of lobar ICH are of particular interest.

The deposition of $\beta$-amyloid peptide in the media of cortical and leptomeningeal arteries, arterioles and capillaries-now known as cerebral amyloid angiopathy (CAA) - was first identified in the early 20 th century. ${ }^{7}$ CAA is quite prevalent in cognitively unimpaired elderly people and even more prevalent in those with dementia. ${ }^{9}$ Since the late 1970s, influential case series have suggested that CAA may cause lobar $\mathrm{ICH}^{10}{ }^{11}$ However, in everyday clinical practice, ${ }^{12}$ CAA is often inferred to be the cause of lobar or cerebellar ICH, especially if the patient is elderly, the ICHs are recurrent or multifocal or haem sensitive gradient recalled echo (GRE) MRI sequences demonstrate at least one lobar brain microbleed. ${ }^{13}$

However, the strength of the overall association between CAA and ICH remains to be precisely quantified (in lobar and cerebellar locations in particular, but also in deep locations), ${ }^{14}$ so we performed a systematic review and meta-analysis of published neuropathological studies. We aimed to take account of three potential confounding factors that should be described, and preferably controlled or adjusted for in comparisons of cases and controls: first, patient age, given the increasing CAA prevalence with age; second, cognitive impairment (and its severity), given the greater prevalence of CAA in those with cognitive impairment than in those without dementia ${ }^{9}{ }^{15}$; and third, patients' racial origins, given racial differences in the prevalence of apolipoprotein E polymorphisms which have been associated with ICH due to $\mathrm{CAA}^{16}{ }^{17}$ and racial differences in the proportion of $\mathrm{ICH}$ in a lobar location. ${ }^{18}$

\section{METHODS}

\section{Search strategy and selection criteria}

In April 2011, two authors (NS and RASS) searched Ovid Medline (1950-) and Embase (1980-) using comprehensive electronic search strategies (see supplement for more details, available online only). One author (NS) also searched the bibliographies of relevant publications and Google Scholar for other papers citing each included paper. We also searched the tables of contents of several journals Journal of Neurology, Neurosurgery and Psychiatry; Lancet Neurology; Annals of Neurology; Brain; Lancet; Neurology; and Stroke) from 2005 and our personal files.

\section{Eligibility criteria}

Studies were eligible for inclusion if they had diagnosed CAA on pathological examination of a brain biopsy or autopsy and quantified the prevalence of 
CAA in patients with spontaneous (non-traumatic) ICH as well as a group of patients without ICH.

\section{Data collection}

Two authors (NS and RASS) screened all titles and abstracts for eligibility, removed duplicates and read the full text of articles that were potentially eligible for inclusion. Eligible studies were read in full by two authors (NS, RASS) who extracted data independently on the following: study design, types of cases and controls, methods of assessment and grading of CAA, prevalence of CAA in cases and controls, and whether any confounders were accounted for. We resolved disagreements by discussion. If pertinent study attributes or data were unavailable or unclear in an eligible publication, we sought clarification from the authors by post and email. We also sought individual patient data from included publications-either in person or by email and post-in order to stratify or adjust the analyses for the potential confounding variables of age and comorbid cognitive impairment, as well as to explore the strength of the association between ICH and CAA according to the neuropathological severity of CAA; unfortunately, only one study provided these data, precluding an individual patient data meta-analysis. ${ }^{14}$

\section{Methodological assessment}

NS was guided in her assessment of the methodological quality of the included studies by the Newcastle-Ottawa scale, ${ }^{19}$ which uses eight items to judge the quality of case control studies on their selection of study groups, the comparability of their cases and controls, and their ascertainment of exposure of cases and controls (ie, to CAA). If a study fulfils the criteria for an item, a score of 1 point is allocated, with the exception of compara- bility which can score up to 2 points, resulting in a maximum score of 9 points.

\section{Statistical analysis}

If we identified multiple publications relating to the same cohort, we included the largest study. For each study, we determined the numbers of cases and controls and the prevalence of CAA in each group. We sought to stratify our analyses by ICH location (deep, lobar, cerebellar or all locations grouped together), age, neuropathological ratings of CAA severity and racial origin of the participants. We meta-analysed the data in StatsDirect statistical software V.2.7.8, using a random effects model with Der Simonian-Laird weights, quantified the strength of any association using OR and its associated 95\% CI, and assessed inconsistency with the $\mathrm{I}^{2}$ statistic. In a separate sensitivity analysis, we tested whether the restriction of our analysis to studies explicitly stating that all ICH were non-traumatic changed the direction or strength of the association between $\mathrm{CAA}$ and $\mathrm{ICH}$ in all locations. In subgroup analyses, we examined the strength of the relationship between CAA and cases with lobar ICH in studies where the average ages of cases and controls were comparable versus those where average ages of cases and controls were dissimilar or unknown, and in studies in which participants were Asian versus those in which they were not.

\section{RESULTS}

Our search strategies identified 1824 articles, of which 19 appeared to be eligible (figure 1). We excluded nine studies because they provided insufficient data to quantify the numbers of cases and controls with and without CAA in seven studies, ${ }^{20-26}$ cases were selected only if they were affected by
Figure 1 Selection of studies included in the systematic review.

\section{IDENTIFICATION}

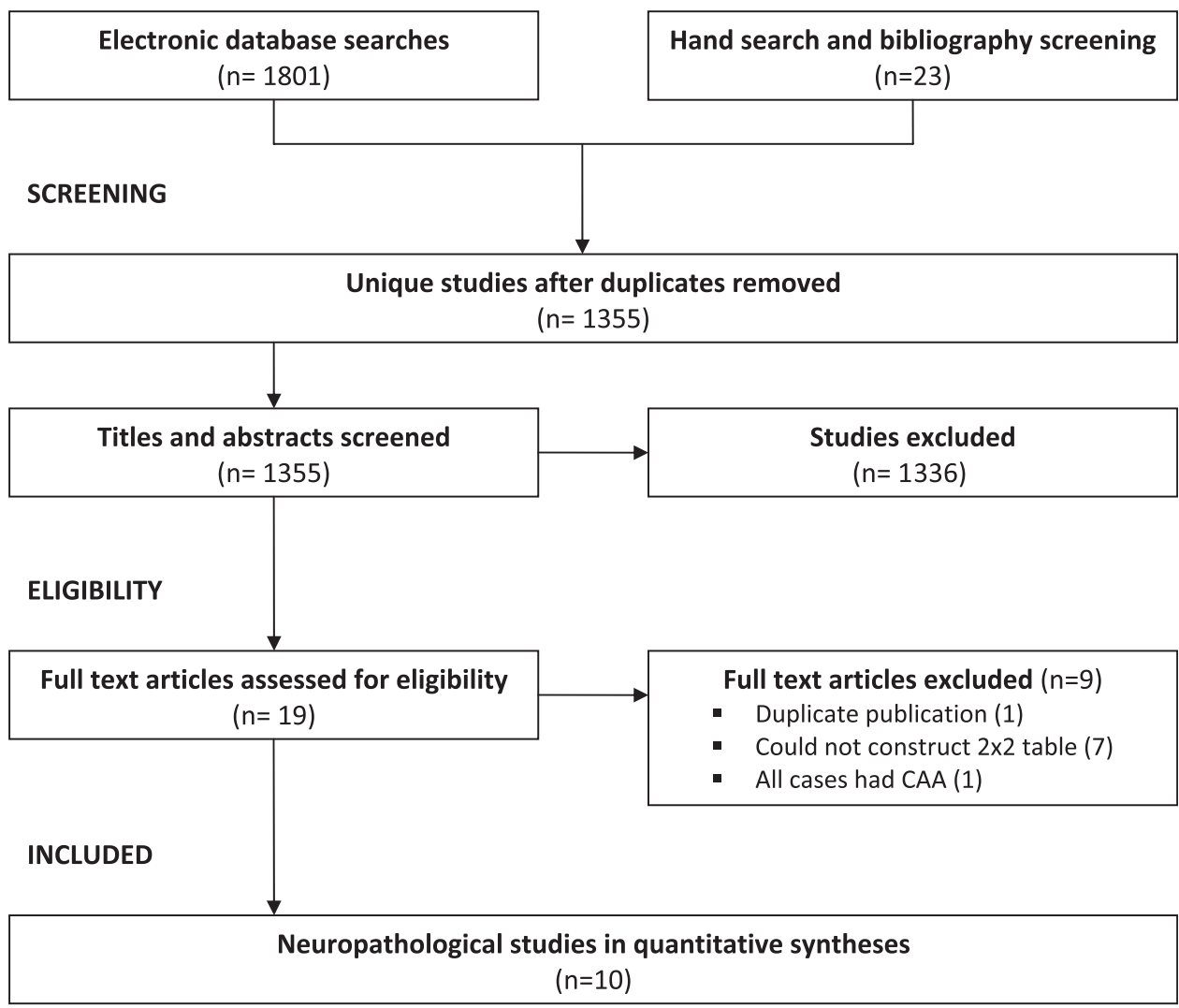


$\mathrm{CAA}^{27}$ and the remaining study reported data already included in this systematic review. ${ }^{28}$ We included 10 neuropathological studies involving 481 cases and 3219 controls from China, ${ }^{29} 30$ Japan, ${ }^{15}{ }^{31}$ Chile, $^{32}$ India, ${ }^{33}$ Australia ${ }^{34}$ and Europe. ${ }^{14} 3536$

\section{Critical appraisal}

We compared included studies to the ideal design for a study of the association between CAA and lobar ICH (box 1) and rated them using the Newcastle-Ottawa scale (table 1).

\section{Selection of study groups}

Studies' ascertainment of cases ranged from highly representative samples of deaths in a community to consecutive, randomly sampled or selected hospital autopsies (table 1). Eight studies clearly defined their cases as having spontaneous ICH ${ }^{14} 29-333536$ and the corresponding author confirmed that ICH cases were spontaneous in another study. ${ }^{34}$ Five studies stated that the ICH had been clinically symptomatic. ${ }^{14} \quad 29 \quad 32 \quad 33 \quad 36$ Two studies included both first ever and recurrent $\mathrm{ICH}^{35} 36$ but the remainder did not specify the inception point for ICH cases. Only five studies described the ages of included cases. ${ }^{14} 31323536$ Three

Box 1 Ideal design of a pathological study of the association between cerebral amyloid angiopathy (CAA) and spontaneous intracerebral haemorrhage (ICH)

\section{Selection of cases and controls}

- Representative sample of cases, with ascertainment clearly defined

- Independent validation of case diagnosis

- Clinical features described

- Incident cases of ICH, recruited at a specified inception point, described in relation to the time of neuropathological examination

- Spontaneous and traumatic ICH distinguished

- First ever and recurrent ICH distinguished

- Radiological confirmation of ICH diagnosis and its anatomical distribution, using a standardised classification of lobar versus deep ICH (whose interobserver reliability has been assessed)

- Appropriate controls

- Derived from the same population as cases

- Ascertained in the same way as the cases

- Without a history of ICH (if cases were first ever diagnoses)

- Quantification of eligible cases and controls not included or omitted from analyses

\section{Assessment of CAA}

- Pathologically confirmed either at tissue biopsy or at postmortem examination

- Detected and rated blind to relevant clinical information

- Methods of tissue preparation, staining and analysis identical for all cases and controls

- Rated according to a standard or externally validated rating scale, and severity specified

- Anatomical location specified in relation to ICH

Reporting and analysis

- Presentation of summary data, stratified by ICH location, age of person, past history of cognitive impairment

- Cases and controls matched for major confounders (ie, age and past history of cognitive impairment) or confounders adjusted for in the analysis

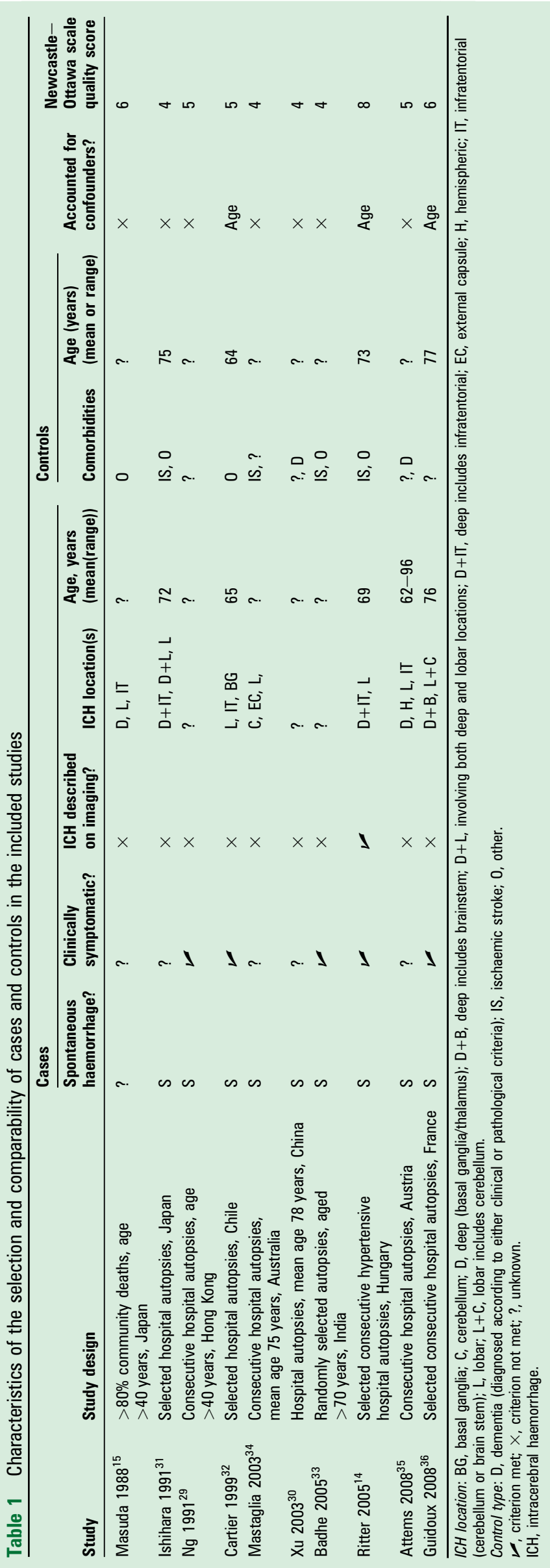


studies did not systematically specify ICH locations ${ }^{29} 3033$ but the remainder did, albeit with different categories (table 1). Furthermore, studies varied in their definitions of 'lobar' ICH, including: ICH that had originated in the cerebellum, ${ }^{36}$ cortex or subarachnoid space ${ }^{31}$; subcortical, cortical or in the insular cortex closely related to the basal ganglia ${ }^{14}$; and in another, lobar ICH was distinguished from multiple cortico-subcortical $\mathrm{ICH}^{35}$

\section{Comparability of cases and controls}

All but one study ${ }^{33}$ described ascertainment of controls from the same population as the cases (consecutive hospital autopsy controls, ${ }^{29303435}$ selected hospital autopsy controls ${ }^{14313236}$ and community controls), ${ }^{15}$ such that the controls could have been cases had they been affected by ICH (table 1). In four studies, $16-82 \%$ of the control groups had ischaemic stroke. ${ }^{14} 3133$ Considering potential confounding factors, two studies included controls with dementia diagnosed on clinical and neuropathological grounds, ${ }^{30} 3435$ only five studies described the average ages of their cases ${ }^{1431323536}$ and only four studies described the average ages of their controls, ${ }^{14} 313236$ but just three studies accounted for confounding by matching the ages of cases and controls within 5 years. ${ }^{14} 3236$

\section{Ascertainment of exposure of cases and controls}

All but one study ${ }^{36}$ assessed cases and controls for CAA in the same way (table 2) but only one study ${ }^{32}$ reported that the assessment was blinded (although the nature of blinding was unclear). The extent of sampling varied between studies (table 2). Eight studies used Congo Red staining to detect CAA, ${ }^{14} 15$ 29-33 36 one of which also used immunohistochemistry in every case. ${ }^{30}$ The rating of CAA severity involved a variety of rating scales - many of which were bespoke, being devised by the authors themselves (table 2)-and CAA severity in cases and controls was seldom quantified in every patient. Following communication with the corresponding author of one study, ${ }^{14}$ we established that only four studies described whether CAA was specifically present in the vessels adjacent to the ICH (so that lobar ICH could be attributed to lobar CAA). ${ }^{15}$ 29-31

\section{Association between CAA and ICH}

Our meta-analyses did not reveal an association between CAA and ICH in any location in all 10 studies (OR 1.21, 95\% CI 0.87 to 1.68 ; $\mathrm{I}^{2} 29 \%$; figure 2 ) nor in a sensitivity analysis omitting one study that might have included traumatic ICH (OR 1.19, 95\% CI 0.84 to 1.67$).{ }^{15}$ There was no significant association between CAA and deep ICH (OR 0.81, 95\% CI 0.30 to 2.19; five studies, $\left.\mathrm{I}^{2} 58 \%\right)^{14} 15323435$ or cerebellar ICH, although there were only eight cases of cerebellar ICH (OR 2.05, 95\% CI 0.55 to 7.63; four studies, $\left.\mathrm{I}^{2} 0 \%\right) .{ }^{15} 303435$ However, CAA was more prevalent in lobar ICH cases $(54 / 105,51 \%)$ in comparison with controls $(1119 / 2629,43 \%)$ (OR 2.21, 95\% CI 1.09 to 4.45 ; six studies, $\left.I^{2} 40 \%\right) .{ }^{14} 153132 \quad 3435$ In subgroup analyses of the association between CAA and lobar ICH, the association remained in the three studies where the average ages of the cases and controls were comparable (OR 3.24, 95\% CI 1.02 to 10.26), ${ }^{14} 3132$ but not in those where ages were dissimilar or unknown (OR 1.58, 95\% CI 0.91 to 2.77). ${ }^{15} 3435$ We could not demonstrate that the association between CAA and lobar ICH was different in studies of Asian patients (OR 3.02, 95\% CI 0.44 to 20.77$)^{1531}$ or patients of other ethnic origins (OR $1.89,95 \%$ CI 0.86 to 4.15$).{ }^{1432} 3435$

\section{DISCUSSION}

In our systematic review and meta-analysis of 10 neuropathological cross sectional or case control studies involving 481 cases and 3219 controls, we found a significant association between CAA and lobar ICH but not with ICH in other locations (figure 2).

This association between CAA and lobar ICH might have been even stronger had the included studies accounted for potential confounding factors (eg, age, severity of cognitive impairment, ethnic origin and possibly prior ischaemic stroke), ${ }^{40}$ included a consistent definition of 'lobar' $\mathrm{ICH}^{16}$ and focused on the prevalence of severe CAA (and other vasculopathic features, such as microaneurysms) in the blood vessels that were anatomically related to the $\mathrm{ICH}$. The association might also have been stronger had the cases been selected according to the Boston diagnostic criteria, which 'definitely' attribute the cause of lobar ICH to CAA if there is pathological evidence of severe CAA with vasculopathy at postmortem. ${ }^{13} 4142$ The Boston criteria for 'probable CAA' have an excellent specificity and therefore do not misclassify people who have lobar ICH without underlying severe CAA $(100 \%, 95 \%$ CI $77 \%$ to $100 \%),{ }^{13}$ but the sensitivity of these criteria for 'probable CAA' was $44 \%$ (95\% CI $28 \%$ to $62 \%$ )

Table 2 Characteristics of the assessment of exposure in the included studies

\begin{tabular}{|c|c|c|c|c|c|c|}
\hline \multirow[b]{2}{*}{ Study } & \multirow{2}{*}{$\begin{array}{l}\text { No of tissue } \\
\text { blocks examined }\end{array}$} & \multirow{2}{*}{$\begin{array}{l}\text { Locations } \\
\text { examined in cases }\end{array}$} & \multirow{2}{*}{$\begin{array}{l}\text { Locations examined } \\
\text { in controls }\end{array}$} & \multicolumn{2}{|c|}{ Cerebral amyloid angiopathy detection } & \multirow{2}{*}{$\begin{array}{l}\text { Rating of severity } \\
\text { of CAA }\end{array}$} \\
\hline & & & & Congo Red stain & Immunohistochemistry & \\
\hline Masuda $1988^{15}$ & 6 & $B G, H C, I \dagger \dagger, L$ & $B G, H C, L$ & $\swarrow$ & $\times$ & Bespoke \\
\hline Ishihara $1991^{31}$ & $?$ & $\mathrm{~B}, \mathrm{C}, \mathrm{GM}, \mathrm{I}, \mathrm{L}$ & $\mathrm{B}, \mathrm{C}, \mathrm{GM}, \mathrm{L}$ & $\swarrow$ & $S$ & Bespoke \\
\hline $\mathrm{Ng} 1991^{29}$ & $?$ & $\mathrm{I}, ?$ & $\mathrm{HC}, \mathrm{L}^{*}$ & $\swarrow$ & $x$ & Vinters $^{38}$ \\
\hline Cartier $1999^{32}$ & $?$ & $B, B G, C, L^{* *}$ & $B, B G, C, L^{* *}$ & $\swarrow$ & $x$ & Presence/absence \\
\hline Mastaglia $2003^{34}$ & $2-6$ & $\mathrm{I}, \mathrm{L} \dagger$ & $\mathrm{I}, \mathrm{L} \dagger$ & $\times$ & $\nu$ & Bespoke \\
\hline $\mathrm{Xu} 2003^{30}$ & $?$ & I††? & ? & $\nu$ & $\nu$ & Bespoke \\
\hline Badhe $2005^{33}$ & $10-12$ & $B G, C, H C, L$ & $B G, C, H C, L$ & $\nu$ & $\times$ & Vinters $^{38}$ \\
\hline Ritter $2005^{14}$ & $4-5$ & $B G, C, I, L \neq$ & $B G, C, L \neq$ & $\swarrow$ & $x$ & Vonsattel $^{27}$ \\
\hline Attems $2008^{35}$ & $?$ & $B, B G, C, L \S$ & $B, B G, C, L \S$ & $\times$ & $\nu$ & Olichney $^{39} \&$ bespoke \\
\hline Guidoux $2008^{36}$ & $3-5 \neq \ddagger$ & $?$ & $B, B G, C, H C, L \Phi$ & レキキ & $\nu \S \S$ & Presence/absence \\
\hline
\end{tabular}

Locations: B, brainstem; BG, basal ganglia; C, cerebellum; GM, central grey matter; HC, hippocampus; I, site of ICH; L, lobar (every lobe unless *parieto-occipital only; †frontal, temporal and parietal only; ‡frontoparietal and occipital only; §frontal, temporal and occipital only; 9 temporal and occipital only; ${ }^{* *}$ not specified).

t†Presence of CAA specified in vessels at the site of the ICH in CAA positive cases, but unclear whether this was done for all cases.

$\ddagger \ddagger$ Cases but not controls.

$\S \S$ Controls but not cases.

$\mathscr{V}$, criterion met; $\times$, criterion not met; ?, unknown; $S$, some.

CAA, cerebral amyloid angiopathy; ICH, intracerebral haemorrhage. 
Figure 2 OR meta-analysis. Cerebral amyloid angiopathy prevalence in cases with intracerebral haemorrhage (ICH) (stratified by location) versus controls. Squares are point estimates of the studies, error bars are $95 \% \mathrm{Cls}$ and diamonds represent pooled summary estimates (whose width is their 95\% Cl).
Study

Controls n/N (\%)Cases n/N (\%)

$\mathrm{OR}(95 \% \mathrm{Cl})$

$\begin{array}{lll}\text { Masuda } & 88 / 374(24 \%) & 3 / 26(12 \%) \\ \text { Ishihara } & 34 / 119(29 \%) & 19 / 50(38 \%) \\ \mathrm{Ng} & 21 / 210(10 \%) & 4 / 49(8 \%) \\ \text { Cartier } & 13 / 30(43 \%) & 19 / 37(51 \%) \\ \text { Xu } & 93 / 297(31 \%) & 21 / 65(32 \%) \\ \text { Mastaglia } & 26 / 96(27 \%) & 0 / 4(0 \%) \\ \text { Badhe } & 3 / 24(13 \%) & 1 / 12(8 \%) \\ \text { Ritter } & 5 / 65(8 \%) & 15 / 64(23 \%) \\ \text { Attems } & 953 / 1,945(49 \%) & 56 / 115(49 \%) \\ \text { Guidoux } & 9 / 59(15 \%) & 18 / 59(31 \%)\end{array}$

Any ICH location: $p=0.3$ (I-squared=29\%)

$\begin{array}{lll}\text { Masuda } & 88 / 374(24 \%) & 0 / 2(0 \%) \\ \text { Ishihara } & 34 / 119(29 \%) & 9 / 13(69 \%) \\ \text { Cartier } & 13 / 30(43 \%) & 6 / 14(43 \%) \\ \text { Mastaglia } & 26 / 96(27 \%) & 0 / 2(0 \%) \\ \text { Ritter } & 5 / 65(8 \%) & 8 / 24(33 \%) \\ \text { Attems } & 953 / 1,945(49 \%) 31 / 50(62 \%)\end{array}$

Lobar ICH: $p=0.03$ (I-squared $=40 \%$ )

$\begin{array}{lll}\text { Masuda } & 88 / 374(24 \%) & 1 / 1(100 \%) \\ \text { Xu } & 93 / 297(31 \%) & 2 / 4(50 \%) \\ \text { Mastaglia } & 26 / 96(27 \%) & 0 / 1(0 \%) \\ \text { Attems } & 953 / 1,945(49 \%) 1 / 2(50 \%)\end{array}$

Cerebellar ICH: $p=0.3$ (I-squared $=0 \%$ )

$\begin{array}{lll}\text { Masuda } & 88 / 374(24 \%) & 0 / 23(0 \%) \\ \text { Cartier } & 13 / 30(43 \%) & 9 / 18(50 \%) \\ \text { Mastaglia } & 26 / 96(27 \%) & 0 / 1(0 \%) \\ \text { Ritter } & 5 / 65(8 \%) & 7 / 40(18 \%) \\ \text { Attems } & 953 / 1,945(49 \%) & 11 / 35(31 \%)\end{array}$

Deep ICH: $p=0.7$ (I-squared $=58 \%$ ) and their negative predictive value was 39\% (95\% CI $22 \%$ to $58 \%$ ), because more than half of the people with lobar ICH and severe CAA were not identified by the 'probable' criteria. ${ }^{13}$ Both systematic use of GRE MRI to identify brain microbleeds and the inclusion of superficial siderosis in the Boston criteria have improved their diagnostic accuracy ${ }^{42}$ but false positives and false negatives still exist and the role of other degrees of CAA severity in causing lobar ICH remains to be clarified, given that the studies in this meta-analysis were unable to do so.

This meta-analysis benefited from thorough ascertainment of pertinent studies, comprehensive critical appraisal to determine their inclusion, clarification by correspondence with study authors and a large number of cases and controls in our analyses. It is reassuring that our finding of an overall association between lobar ICH and CAA was confirmed by the three studies in which minimal confounding by patient age was evident. ${ }^{14} 3134$ Unfortunately, only three of the included studies assessed the association of CAA and ICH having taken other competing risk factors for ICH into account, ${ }^{14} 3136$ and just two studies described the influence on the association of other potential effect modifiers (Alzheimer-type pathology ${ }^{35}$ and antithrombotic drugs). ${ }^{14}$ Further confirmation of the direction of this 
association between CAA and lobar ICH, and exploration of the strength of the association, could only arise from further research with an ideal study design (box 1), given that an individual patient data meta-analysis was impossible.

The prevalence of CAA in patients with lobar ICH and the strength of the overall association between CAA and lobar ICH (figure 2), as well as the diagnostic accuracy of the Boston criteria for ICH due to CAA, ${ }^{13} 42$ are consistent with CAA being one of several potential causes of lobar ICH in the elderly. Although we have demonstrated an association between CAA and lobar ICH, this does not necessarily imply causation. Of Sir Austin Bradford Hill's nine criteria ${ }^{43}$ that would support an association being causal (see supplementary table 4, available online only), CAA is a plausible cause of lobar $\mathrm{ICH},{ }^{44}$ but further work is required to more reliably establish the association's strength, demonstrate its consistency and evaluate its biological gradient. ${ }^{43}$ If the methodological problems noted above are addressed and cases of lobar ICH are carefully phenotyped (according to their history of transient neurological events and cognitive impairment, and the presence of strictly lobar brain microbleeds on GRE MRI and superficial siderosis), ${ }^{42}$ then the strength of the association between CAA and lobar ICH would likely be much stronger. However, understanding whether milder degrees of CAA are associated with lobar ICH is also important to investigate the biological gradient and explore whether there are interactions with CAA of milder severity that might precipitate ICH.

Future research should include well designed case control and cohort studies to explore the CAA-ICH association (and its effect modifiers), ${ }^{37}$ individual patient data meta-analyses of comparable studies, further comparisons of the sensitivity and specificity of different methods of CAA detection (such as Congo Red staining versus immunohistochemistry) ${ }^{45}$ and the development and validation of a unified rating scale for CAA distribution and severity. ${ }^{46}$

Funding NS was funded by a clinical research training fellowship from the UK Medical Research Council and The Stroke Association. RASS was funded by a clinician scientist fellowship from the UK Medical Research Council.

\section{Competing interests None.}

Contributors Agree with the manuscript results and conclusions: NS, CS, RASS Designed the experiments/study: RASS. Analyzed the data: NS, RASS. Collected data/did experiments for the study: NS, CS, RASS. Wrote the first draft of the paper: NS, RASS. Contributed to the writing of the paper: NS, CS, RASS.

Provenance and peer review Not commissioned; externally peer reviewed.

\section{REFERENCES}

1. Feigin VL, Lawes CM, Bennett DA, et al. Worldwide stroke incidence and early case fatality reported in 56 population-based studies: a systematic review. Lancet Neurol 2009:8:355-69

2. van Asch CJ, Luitse MJ, Rinkel GJ, et al. Incidence, case fatality, and functional outcome of intracerebral haemorrhage over time, according to age, sex, and ethnic origin: a systematic review and meta-analysis. Lancet Neurol 2010;9:167-76.

3. Ariesen MJ, Claus SP, Rinkel GJ, et al. Risk factors for intracerebral haemorrhage in the general population: a systematic review. Stroke 2003;34:2060-5

4. Chapman N, Huxley R, Anderson C, et al. Effects of a perindopril-based blood pressure-lowering regimen on the risk of recurrent stroke according to stroke subtype and medical history: the PROGRESS Trial. Stroke 2004:35:116-21

5. Arima H, Tzourio C, Anderson C, et al. Effects of perindopril-based lowering of blood pressure on intracerebral hemorrhage related to amyloid angiopathy: the PROGRESS trial. Stroke 2010;41:394-6.

6. Bailey RD, Hart RG, Benavente 0, et al. Recurrent brain hemorrhage is more frequent than ischemic stroke after intracranial hemorrhage. Neurology 2001:56:773-7.

7. Oppenheim G. Uber "drusige Nekrosen" in der Großhirnrinde. Neurol Centralb/ 1909;28:410-13.
8. Scholz W. Studien zur Pathologie der Hirngefäße II. Die drusige Entartung der Hirnarterien und-capillaren (Eine Form seniler Gefässerkrankung). Zeitshrift für die gesamte Neurologie und Psychiatrie 1938;162:694-715.

9. Neuropathology Group of the Medical Research Council Cognitive Function and Ageing Study (MRC CFAS). Pathological correlates of late-onset dementia in a multicentre, community-based population in England and Wales. Lancet 2001;357:169-75.

10. Jellinger K. Cerebrovascular amyloidosis with cerebral hemorrhage. J Neurol 1977:214:195-206.

11. Okazaki H, Reagan TJ, Campbell RJ. Clinicopathologic studies of primary cerebral amyloid angiopathy. Mayo Clin Proc 1979;54:22-31.

12. Cordonnier C, Klijn CJ, van Beijnum J, et al. Radiological investigation of spontaneous intracerebral hemorrhage: systematic review and trinational survey. Stroke 2010:41:685-90.

13. Knudsen KA, Rosand J, Karluk D, et al. Clinical diagnosis of cerebral amyloid angiopathy: validation of the Boston criteria. Neurology 2001;56:537-9.

14. Ritter MA, Droste DW, Hegedus $\mathrm{K}$, et al. Role of cerebral amyloid angiopathy in intracerebral hemorrhage in hypertensive patients. Neurology 2005;64:1233-7

15. Masuda J, Tanaka K, Ueda K, et al. Autopsy study of incidence and distribution of cerebral amyloid angiopathy in Hisayama, Japan. Stroke 1988;19:205-10.

16. Biffi A, Sonni A, Anderson CD, et al. Variants at APOE influence risk of deep and lobar intracerebral hemorrhage. Ann Neurol 2010;68:934-43.

17. Corbo RM, Scacchi R. Apolipoprotein E (APOE) allele distribution in the world. Is APOE*4 a 'thrifty' allele? Ann Hum Genet 1999;63:301-10.

18. Lavados PM, Sacks C, Prina L, et al. Incidence of lobar and non-lobar spontaneous intracerebral haemorrhage in a predominantly Hispanic-Mestizo population-the PISCIS stroke project: a community-based prospective study in Iquique, Chile. Neuroepidemiology 2010;34:214-21.

19. Wells GA, Shea B, O'Connell D, et al. The Newcastle-Ottawa Scale (NOS) for assessing the quality of nonrandomised studies in meta-analyses. 2001. http://www ohri.ca/programs/clinical epidemiology/oxford.htm (accessed 20 Oct 2011).

20. Tomonaga M. Cerebral amyloid angiopathy in the elderly. J Am Geriatr Soc 1981;29:151-7.

21. Itoh Y, Yamada M. Cerebral amyloid angiopathy in the elderly: the clinicopathological features, pathogenesis, and risk factors. J Med Dent Sci 1997:44:11-19.

22. Yamada M, Tsukagoshi $\mathrm{H}$, Otomo $\mathrm{E}$, et al. Cerebral amyloid angiopathy in the aged J Neurol 1987;234:371-6.

23. Itoh $\mathrm{Y}$, Yamada $\mathrm{M}$, Hayakawa $\mathrm{M}$, et al. Cerebral amyloid angiopathy: a significant cause of cerebellar as well as lobar cerebral hemorrhage in the elderly. J Neurol Sci 1993;116:135-41.

24. Yamanouchi H, Shimada H, Kuramoto K. Subtypes and proportions of cerebrovascular disease in an autopsy series in a Japanese geriatric hospital. Klin Wochenschr 1990;68:1173-7.

25. Ellis RJ, Olichney JM, Thal LJ, et al. Cerebral amyloid angiopathy in the brains of patients with Alzheimer's disease: the CERAD experience, Part XV. Neurology 1996;46:1592-6.

26. Jellinger K. Spatial distribution of haemorrhages in cerebral amyloid angiopathy Ann Neurol 2006;59:215.

27. Vonsattel JP, Myers RH, Hedley-Whyte ET, et al. Cerebral amyloid angiopathy without and with cerebral hemorrhages: a comparative histological study. Ann Neurol 1991;30:637-49

28. Jellinger KA, Lauda F, Attems J. Sporadic cerebral amyloid angiopathy is not a frequent cause of spontaneous brain hemorrhage. Eur $\mathrm{J}$ Neurol 2007:14:923-8.

29. Ng TH, Leung SY, Wong MP. Cerebral amyloid angiopathy in Chinese: incidence and significance. Clin Neurol Neurosurg 1991;93:19-23.

30. Xu D, Yang C, Wang L. Cerebral amyloid angiopathy in aged Chinese: a cliniconeuropathological study. Acta Neuropathol 2003:106:89-91.

31. Ishihara T, Takahashi M, Yokota T, et al. The significance of cerebrovascular amyloid in the aetiology of superficial (lobar) cerebral haemorrhage and its incidence in the elderly population. J Pathol 1991;165:229-34.

32. Cartier L, Araya F, Avendano R, et al. Hemorragias cerebrales y angiopatía amiloidea. Rev Med Chile 1999:127:295-303

33. Badhe PB, Mehta NK, Desai AP. Cerebral amyloid angiopathy: an Indian study Bombay Hospital Journal 2005;47. http://www.bhj.org/journal/2005_4701 jan/html/ original t cerebral.htm (accessed 20 Oct 2011).

34. Mastaglia FL, Byrnes ML, Johnsen RD, et al. Prevalence of cerebral vascular amyloid-beta deposition and stroke in an aging Australian population: a postmortem study. J Clin Neurosci 2003;10:186-9.

35. Attems J, Lauda F, Jellinger KA. Unexpectedly low prevalence of intracerebral hemorrhages in sporadic cerebral amyloid angiopathy: an autopsy study. J Neurol 2008:255:70-6.

36. Guidoux C. Causes des Hémorragies Intracérébrales: Etude Neuropathologique. Paris: Université Paris Val-De-Marne, 2008:1-67.

37. Schulz KF, Grimes DA. Case control studies: research in reverse. Lancet 2002;359:431-4.

38. Vinters HV, Gilbert JJ. Cerebral amyloid angiopathy: incidence and complications in the aging brain. II. The distribution of amyloid vascular changes. Stroke 1983;14:924-8. 
39. Olichney JM, Hansen LA, Hofstetter CR, et al. Cerebral infarction in Alzheimer's disease is associated with severe amyloid angiopathy and hypertension. Arch Neurol 1995; 52:702-8.

40. Cadavid D, Mena $\mathrm{H}$, Koeller $\mathrm{K}$, et al. Cerebral beta amyloid angiopathy is a risk factor for cerebral ischemic infarction. A case control study in human brain biopsies. J Neuropathol Exp Neurol 2000:59:768-73.

41. Miller JH, Wardlaw JM, Lammie GA. Intracerebral haemorrhage and cerebral amyloid angiopathy: CT features with pathological correlation. Clin Radiol 1999;54:422-9.

42. Linn J, Halpin A, Demaerel P, et al. Prevalence of superficial siderosis in patients with cerebral amyloid angiopathy. Neurology 2010;74:1346-50.
43. Hill $\mathbf{A B}$. The environment and disease: association or causation? Proc $R$ Soc Med 1965; $58: 295-300$.

44. Weller RO, Boche D, Nicoll JA. Microvasculature changes and cerebral amyloid angiopathy in Alzheimer's disease and their potential impact on therapy. Acta Neuropathologica 2009;118:87-102.

45. Haglund M, Englund E. Cerebral amyloid angiopathy, white matter lesions and Alzheimer encephalopathy-a histopathological assessment. Dement Geriatr Cogn Disord 2002;14:161-6.

46. Greenberg SM, Gurol ME, Rosand J, et al. Amyloid angiopathy-related vascular cognitive impairment. Stroke 2004;35:2616-19.

\section{DIFFERENTIAL DIAGNOSIS}

\section{Trustworthy guidance on your iPhone}

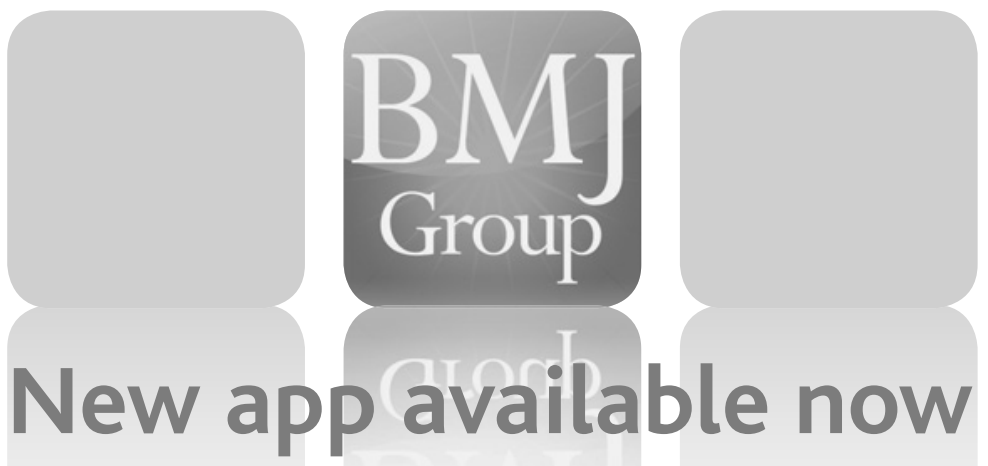

Find out more at bestpractice.bmj.com/differentials 